Background and Aims 314 internationally adopted children were seen between 01/01/2008 and 31/03/2012 at the Institute of Tropical Medicine in Antwerp (Belgium). We describe the prevalence of pathogenic intestinal parasites in this population.

Methods Retrospective analysis of patient records. Feces samples were obtained in 307/314 children. In addition, serology for Strongyloides and Schistosoma was performed.

Results Pathogenic parasites were found in 55.7\% (53\% in children $0-5$ years, $72.1 \%>5$ years). When counting any parasites, $65.9 \%$ of children were found positive ( $61.4 \%$ for $0-5$ years, $93 \%$ for $>5$ years).

$37.5 \%$ of children with positive samples had $\geq 3$ parasites. Analysis by age in children from the 4 most represented countries ( $n=285)$ is shown in table.

Abstract 931 Table 1 Percentage of children with parasites

\begin{tabular}{lcccccccc}
\hline & \multicolumn{2}{c}{ Ethiopia } & \multicolumn{2}{c}{ China } & \multicolumn{2}{c}{ Kazakhstan } & \multicolumn{2}{c}{ India } \\
\hline & $0-5 y r$ & $>5 y r$ & $0-5 y r$ & $>5 y r$ & $0-5 y r$ & $>5 y r$ & $0-5 y r$ & $>5 y r$ \\
& $(n=180)$ & $(n=36)$ & $(n=28)$ & $(n=3)$ & $(n=21)$ & $(n=1)$ & $(n=13)$ & $(n=3)$ \\
Giardia lamblia & $43.9 \%$ & $52.8 \%$ & $3.6 \%$ & $33.3 \%$ & $4.8 \%$ & $0 \%$ & $61.5 \%$ & $0 \%$ \\
Dientamoeba & $1.7 \%$ & $2.8 \%$ & $0 \%$ & $0 \%$ & $14.2 \%$ & $100 \%$ & $7.7 \%$ & $0 \%$ \\
fragilis & & & & & & & & \\
Hymenolepis nana & $13.9 \%$ & $25 \%$ & $0 \%$ & $0 \%$ & $0 \%$ & $0 \%$ & $38.5 \%$ & $66.7 \%$ \\
Ankylostoma & $5.6 \%$ & $16.7 \%$ & $0 \%$ & $0 \%$ & $0 \%$ & $0 \%$ & $0 \%$ & $0 \%$ \\
Strongyloides & $21.1 \%$ & $16.7 \%$ & $3.6 \%$ & $0 \%$ & $9.5 \%$ & $0 \%$ & $23.1 \%$ & $66.7 \%$ \\
Schistosoma & $2.8 \%$ & $11.1 \%$ & $0 \%$ & $0 \%$ & $0 \%$ & $0 \%$ & $0 \%$ & $0 \%$ \\
Ascaris & $2.2 \%$ & $0 \%$ & $0 \%$ & $0 \%$ & $4.8 \%$ & $0 \%$ & $0 \%$ & $0 \%$ \\
Trichuris & $6.1 \%$ & $19.4 \%$ & $0 \%$ & $0 \%$ & $0 \%$ & $0 \%$ & $0 \%$ & $0 \%$ \\
trichuria & & & & & & & & \\
\hline
\end{tabular}

Conclusion There is a high prevalence of pathogenic intestinal parasites in IAC: $53 \%$ in children $0-5$ years and $72.1 \%$ in children $>5$ years.

\section{COMPARISON OF C- REACTIVE PROTEIN WITH LEUKOCYTES AND ESR FOR DIFFERENTIATION BETWEEN BACTERIAL AND VIRAL INFECTIONS}

doi:10.1136/archdischild-2012-302724.0932

${ }^{1} \mathrm{C}$ Zavarache, ${ }^{2} \mathrm{M}$ Neamtu, ${ }^{1,3} \mathrm{O}$ Falup-Pecurariu. ${ }^{1}$ Department of Pediatrics, University Children's Hospital, Brasov; 'Lucian Blaga University, Sibiu; ${ }^{3}$ Department of Pediatrics, Faculty of Medicine, University Transilvania, Brasov, Romania

Background There are several studies that show the usefulness of inflammatory markers for distinguishing between viral and bacterial infection at children.

Aim of the study To evaluate the usefulness of leukocytes, C-reactive protein (CRP) and erythrocyte sedimentation rate (ESR) as markers for differentiation of bacterial infection versus viral infections in children.

Methods Prospective study which evaluated 1482 patients divided into two groups: 1) group A with 777 patients having viral infections and 2) group B with bacterial infections comprised of 705 patients.

Results Mean values for leucocytes were significantly different $(p<0.05)$ for viral infection $10633 \pm 4896 / \mathrm{mm}^{3}$ versus $11475 \pm 5562$ / $\mathrm{mm}^{3}$ for bacterial one.

Mean erythrocyte sedimentation rate (ESR) for viral infection was $17,5 \pm 15.13 \mathrm{~mm} / \mathrm{hr}$ versus $26,72 \pm 24,03 \mathrm{~mm} / \mathrm{hr}$ for bacterial infections $(p<0.05)$. Mean CRP for viral infection was $8,73 \pm 13.34$ $\mathrm{mg} / \mathrm{dl}$ versus $15.46 \pm 28.05 \mathrm{mg} / \mathrm{dl}(\mathrm{p}<0.05)$ for bacterial one. We analyzed the degree in which inflammatory tests may distinguish between the two groups at 24 hours. Mean values for leucocytes was for viral infection $9506 \pm 3548 / \mathrm{mm}^{3}$ versus $10794 \pm 8637 / \mathrm{mm}^{3}(\mathrm{p}<0.05)$ for bacterial one. Mean ESR for viral infection was $12,97 \pm 11,8 \mathrm{~mm} /$ hr versus $28,44 \pm 21 \mathrm{~mm} / \mathrm{hr}$ for bacterial infections $(\mathrm{p}<0.05)$.
Conclusion This study suggests that CRP, ESR and leucocytes are good markers for differentiation between bacterial versus viral infections.

\section{CLINICAL FINDINGS AND LONG-TERM OUTCOME IN INFANTS BORN TO MOTHERS WITH PREEXISTING IMMUNITY TO CYTOMEGALOVIRUS}

doi:10.1136/archdischild-2012-302724.0933

'MG Capretti, 'C Marsico, 'M Spinelli, 'M De Angelis, 'E Tridapalli, ${ }^{2} \mathrm{~T}$ Lazzarotto, ${ }^{2} \mathrm{~A}$ Chiereghin, ${ }^{2} \mathrm{G}$ Piccirilli, 'L Corvaglia, ${ }^{3} \mathrm{M}$ Lanari, ' $\mathrm{G}$ Faldella. 'Department of Obstetrical, Gynaecological and Paediatric Sciences, Operative Unit of Neonatology; ${ }^{2}$ Department of Haematology, Oncology and Laboratory Medicine, Operative Unit of Microbiology and Virology, St. Orsola-Malpighi University Hospital, University of Bologna, Bologna, ${ }^{3}$ Department Paediatrics and Neonatology Unit, S. Maria della Scaletta Hospital, Imola, Italy

Background and Aims Cytomegalovirus (CMV) is the most common viral cause of congenital infection. Preexisting maternal immunity strongly reduce CMV transmission. To characterize newborn findings and long-term outcome in infants born to mothers with non-primary CMV infection.

Methods Prospective study of infants with congenital CMV infection born between 2005 and 2010. Clinical and neuroimaging findings at birth were recorded. Infants were enrolled in a long-term follow-up program including clinical, ophthalmological, audiological and neurodevelopmental examinations.

Results Of the 37 infants with congenital CMV infection identified during the study period, $31 / 37(84 \%)$ were born to mothers with primary CMV infections and 6/37(16\%) were born to mothers with confirmed non-primary CMV infections in pregnancy. Three of 6 infants born to mothers with preexisting immunity had symptoms/ signs at birth: microcephaly (3), petechiae (2), thrombocytopenia (2), hepatosplenomegaly (2), jaundice (1), chorioretinitis (1). These infants showed abnormal auditory brainstem evoked response at first evaluation and abnormal neuroimaging findings. At follow-up $2 / 3$ infants developed severe neurological sequelae (cerebral palsy and epilepsy in 1 case), and $1 / 3$ showed delayed psychomotor development requiring rehabilitation; $3 / 3$ infants had bilateral sensorineural hearing loss. Symptomatic infants were treated with antiviral drugs. The remaining $3 / 6$ infants were asymptomatic at birth and showed a good long-term neurologic outcome.

Conclusions Clinical findings and long-term outcome in infants born to mothers with preexisting CMV immunity are widely variable and may be severe. The presence of symptoms/signs consistent with CMV congenital infection should be closely evaluated even in infants born to mothers with CMV-IgG positivity prior to conception.

\section{PREVALENCE AND RISK FACTORS OF PAEDIATRIC ROTAVIRUS GASTROENTERITIS IN TUNISIA}

doi:10.1136/archdischild-2012-302724.0934

II Bouanene, 'M Soltani, ' $\mathrm{S}$ El Mhamdi, ${ }^{2} \mathrm{~A}$ Trabelsi, ${ }^{3} \mathrm{E}$ Ben Hamida, ${ }^{3} \mathrm{M}$ Ben Ghorbel. ${ }^{1}$ Preventive Medicine and Epidemiology Department, University Hospital of Monastir, University of Monastir, Monastir; 'Laboratory of Bacteriology and Virology, University Hospital Sahloul, Sousse; ${ }^{3}$ Expanded Programme on Immunization (EPI), Ministry of Health, Tunis, Tunisia

Background and Aims Group A rotaviruses are a major cause of severe acute gastroenteritis (AGE) in children under 5 years of age worldwide. The purpose of this study was to estimate the proportion of rotavirus gastroenteritis and identify its determinants among children admitted to Tunisian hospitals.

Methods We set up active rotavirus hospitalization surveillance in 10 Tunisian cities. From May 2009 through October 2010, we enrolled 550 children $<5$ years of age who were hospitalized with a 
diagnosis of AGE. Stool samples were obtained for rotavirus testing and genotype investigation using ELISA and multiplex RT-PCR.

Results The prevalence of rotavirus infection was $27.3 \%$ (95\% CI $23.6-31)$. Infants $<2$ years of age were most frequently affected $(91.6 \%)$. The most dominant rotavirus genotype was G3P [8], which accounted for $40.4 \%$ of cases. On multivariate analysis, rotavirus was significantly associated with the episode occurring in the winter season (aOR 6.73; 95\% CI 3.45-3.31), vomiting (aOR 3.05; 95\% CI 1.37-6.75), fever (aOR 1.84; 95\% CI 1.10-3.07) and dehydration (aOR 8.20; 95\% CI 3.45-19.47).

Conclusion The determination of rotavirus infection prevalence and its risk factors will help us to better understand the epidemiology of the disease in our country in order to develop effective preventive measures, including vaccines.

\section{EVALUATION OF MEASLES OUTBREAK DURING 2010/2011 IN SKOPJE, MACEDONIA}

doi:10.1136/archdischild-2012-302724.0935

'Z Arsenievski, 'L Lazarevska, 'B Danilovska, 'L Badeva, 'L Sinadinovska, 'A Stojanov, 'M Manev, ${ }^{2}$ E Zisovska. 'Epidemiology, Center for Public Health; ${ }^{2}$ Neonatology, Obstetrics and Gynaecology Clinic Skopje, Skopje, FYR Macedonia

Background Due to low rates of vaccination coverage, in mostly rural in Skopje and as a result of military conflict in 2001, lead to spillover of the measles from neighboring countries, where outbreak of measles was already declared.

Methods and materials: Measles reporting is mandatory in Macedonia. Cases analyzed had to meet the national case definition. Case-series investigation were conducted, surveys of rates of vaccination coverage.

Results From 07.09.2010 to 22.07.2011, we have registered 596 cases of measles. Of these 596, twenty five case after getting a negative result from laboratory testing were discarded, so the number of cases of measles in the area of Skopje was $572(\mathrm{Mb}=97.0 / 100.000)$. The first case was during a 13 months of age unvaccinated child. Out of 572 cases of measles 235 (41.0\%) were hospitalized, mostly with severe clinical symptoms. According to the patients vaccination status the conclusion was that: 517 (90.4\%) persons were vaccinated, of which 59 not subject to the vaccination, $19(3.3 \%)$ persons no data, $36(6.3 \%)$ persons were vaccinated, of which a portion of MMR are 30 and 6 with two doses. During the outbreak, laboratory confirmed 84 cases out of 103 taken materials, were positive.

Conclusions The high rate of vaccine coverage in most municipalities in Skopje, unvaccinated children with a first dose and absence of the second dose in the first grade in elementary school, mostly in rural areas affected by the military conflict in 2001, were the cause of measles in epidemic form.

\section{PREVALENCE AND MANIFESTATIONS OF INFECTIOUS MONONUCLEOSIS-LIKE SYNDROME IN A CHILDREN'S HOSPITAL IN GREECE}

doi:10.1136/archdischild-2012-302724.0936

${ }^{1} \mathrm{C}$ Koutsaftiki, ${ }^{2} \mathrm{M}$ Mammas, ${ }^{2} \mathrm{SA}$ Kassina, ${ }^{2} \mathrm{~A}$ Kapetanaki, ${ }^{2} \mathrm{E}$ Kotsari, ${ }^{3} \mathrm{~A}$ Makri, ${ }^{3} \mathrm{~A}$ Voyatzi, ${ }^{2 M}$ Kousouri. 'Pediatrics, Penteli's General Children's Hospital; ${ }^{2} 1$ st Pediatric Department, Penteli's Children's Hospital; ${ }^{3}$ Department of Clinical Microbiology and Immunology, Penteli's Children's Hospital, Athens, Greece

Introduction Infectious Mononucleosis Syndrome (IMS), is characterized by fever, lymphadenopathy, tonsillitis, hepatomegaly, spleenomegaly. Also peripheral lymphocytosis with $>10 \%$ atypical lymphocytes is present. It is attributed mostly to Epstein-Barr virus (EBV), less to Cytomegalovirus (CMV) and rarely to Herpes Simplex Virus (HSV) and others.
Occasionally, atypical manifestations and serious complications might occur.

Objective Estimating the prevalence of the disease, the responsible infectious agents and of the typical and atypical manifestations in pediatric populations.

Material and Methods Within 12months, 700 serum samples were examined, from children 1-15 years old. Specimens' laboratory investigation included: 1) indirect immunofluorescence, detecting IgG-IgM antibodies against EBV's Viral Capsid Antigen (VCA), 2) Immuno Chemistry luminescence determination of CMV's IgGIgM antibodies, 3) EIA, identifying HSV's IgG-IgM antibodies.

Results Typical clinical findings were: prolonged fever (89\%), lymphadenopathy (82\%), tonsillitis $(57 \%)$, hepato-spleenomegaly $(40 \%)$, cough $(20 \%)$ and skin eruption $(10 \%)$. Atypical manifestations were: menimgoencephalitis in 2 children, 22 months and 7 years old (caused by EBV and HSV1 respectively), haemophagocytic lymphoistiocytosis in an 8 year old (by EBV), Gianotti-Crosti syndrome in an 18 months old (by EBV) and pneumonia in a 22 months old (by EBV). In meningoencephalitis, viral DNA was detected using PCR in cerebrospinal fluid while in the remaining cases, positive IgM antibodies were found. Of the 700 children examined, 56 (8\%) had positive serology for EBV, 29 (4.14\%) for CMV and 1 for HSV 1.

Conclusions IMS is often amongst Greek children. $65 \%$ of the cases are attributed to EBV and 35\% to CMV which is in accordance to the international literature.

\section{STUDY OF DETECTION VIBRIO CHOLERAE 01 FROM KAROON RIVER WATERS AHVAZ AND ROLE IN THE PUBLIC HEALTH}

doi:10.1136/archdischild-2012-302724.0937

M Mehdinejad, N NassirAbadi, H Godarzi. Ahvaz Jundishapur University of Medical Sciences (AJUMS), School of Medicine, Dept. of Microbiology, Ahvaz, Iran

Background The watershed of Dez and Karoon rivers located in middle Zagrous mountain with area about 68481-, Thus watershed is a part of Persian gulf watershed. Cholera, an acute intestinal infection caused by the bacterium Vibrio cholerae ( $V$. cholerae) is a historically feared epidemic diarrheal disease that remains a major public health problem in many parts of Africa, Asia, and Latin America. $V$. cholerae $\mathrm{O} 1$ exists as two major serotypes, Inaba and Ogawa, a member of the family Vibrionaceae is transmitted through Fresh water contaminated with fecal matter. Foodborne infections have been traced to raw. The target of study the Segregate $V$. cholerae 01 (Vibrionaceae) in the Karoon Ahvaz River.

Methods In four stages (April, to July 2010), a total 100 samples of water from Karoon River Ahvaz were collected. During the study period the recorded river temperature was about $25-28^{\circ} \mathrm{C}$ and $\mathrm{pH}$ ranged from 7 to 8 . Swabs were cultured onto thiosulphate citrate bile sucrose and MacConkey, and morphological colonies compatible with Vibrio were characterized by oxidase test and agglutinated with antiserum for serotype determination. Also $V$. cholerae biochemical tests with API 20E.

Results From 100 samples of water Karoon River in Ahvaz, Iran, 8 $(8 \%)$ sample were positive for Vibrio cholerae strains. The isolated strains from water Karoon River in Ahvaz, Iran, were Vibrio cholerae O1 (inaba).

Conclusion The priorities for cholera control remain public health interventions through improved water and sanitation, improved surveillance and access to health care facilities, and further development of appropriate vaccines. 